\title{
Increasing the Visibility of Medical Toxicology in the Academic Hospital Setting Through Education
}

\author{
Rebecca E. Bruccoleri
}

Published online: 17 September 2014

(C) American College of Medical Toxicology 2014

Not long ago, I received a consult from the ICU about a patient in profound shock with renal and liver failure. The critical care team was concerned that acetylfentanyl or another drug contaminant contributed to the patient's condition after a recent lecture on "Designer Drugs" I delivered to the Pulmonary and Critical Care Division. Their excellent question to our toxicology service is a prime example of how exposure to the specialty of medical toxicology through a lecture can broaden the differential for a critically ill patient, increase consultations, and provide even more education to an entire medical team.

In healthcare centers that sponsor a medical toxicology fellowship, the education of students, residents, and other healthcare providers is usually the responsibility of the fellow-in-training, and we should embrace this opportunity. Most emergency medicine residencies include some toxicology training and exposure with formal lectures or time on a toxicology service, but that same education is not required for other trainees in other specialties [1, 2]. Overdoses and medication errors can happen on any service at any time, so one my goals during fellowship is to improve medical toxicology education to other specialties. By increasing our presence as educators, we can also increase awareness of medical toxicology as a specialty and even improve patient care as will be seen in a series of upcoming articles in future issues of JMT [3].

There are many opportunities within an academic hospital to become involved in medical education. In an era of limited work hours and resident concern about structured teaching, toxicologists can offer high-yield lectures on a variety of

R. E. Bruccoleri $(\square)$

Harvard Medical Toxicology Fellowship, Division of Emergency

Medicine, Program in Medical Toxicology, Boston Children's

Hospital, 300 Longwood Avenue, Boston, MA 02115, USA

e-mail: Rebecca.Bruccoleri@childrens.harvard.edu topics [4]. Lectures can be given as single events or as part of a curriculum designed for a specific specialty such as internal medicine or pediatrics. Chief residents are almost always in need of speakers for resident didactics and welcome the enthusiasm of toxicology fellows and attendings who want to teach. For example, I worked closely with the chief internal medicine residents to provide interesting toxicology cases for their morning reports while acting as a fellow discussant. Furthermore, ICU rotations often have dedicated didactic time which is a wonderful opportunity to discuss exposures with a high morbidity and mortality as well as current treatment strategies. As medical toxicologists, we are uniquely skilled at linking the pre-clinical basic sciences with clinical care and can reinforce important concepts for all trainee levels. In addition, toxicology cases can be taught using simulation, and a recent study showed a higher retention rate on written tests with simulation compared to lectures [5].

Another method of increasing trainee exposure to toxicology is to offer open electives on the medical toxicology service. These electives can be advertised by curriculum coordinators, during consults, or when giving formal lectures. Other opportunities for educating healthcare personnel include giving CME lectures to off-service attendings and participating in nursing, paramedic, pharmacy, and laboratory staff education. Nurses are great advocates for calling medical toxicology once they understand our role in helping them and their patients. In teaching hospitals they prompt interns and residents on courses of action and can be a friendly reminder to these learners that medical toxicology is available. Furthermore, paramedics call poison centers in the field and appreciate pre-hospital consultation. For pharmacy and laboratory staff, we can provide a clinical context they may lack in other educational opportunities.

Another benefit to becoming a medical educator in toxicology is that it is fun! Residents and students have a real interest in learning about medical toxicology. They 
often have a myriad of questions ranging from management to media reports. They get excited to tell you about their experiences in managing prior toxicology patients and are eager for input on how those cases were managed. Toxicologic exposures stand out to them and are highly memorable.

As medical toxicologists, we are uniquely qualified to collaborate with many specialties, and our presence in the hospital should reflect this ability. We can teach important pharmacologic and toxicologic principles to students and nurses, as well as residents, fellows, and attendings from all specialties. In addition, practicing our specialty through increased consults provides great educational experiences for toxicology fellows and is important for the sustainability of medical toxicology [6]. While the benefits of a bedside consultation service are easier to measure, the impact of educating all health care providers is powerful though harder to quantify. Through medical education, we can both enhance our presence in the hospital and above all, improve the clinical care of medical toxicology patients.
Acknowledgments The author would like to thank Dr. Christine Murphy for her assistance in preparing this editorial.

Sources of Funding None

Conflict of Interest None

\section{References}

1. Ingels M, Marks D, Clark RF (2003) A survey of medical toxicology training in psychiatry residency programs. Acad Psychiatry 27:50-3

2. Jang DH (2010) The impact of a medical toxicology fellowship on the training of future emergency medicine residents. J Med Toxicol 6:371-2

3. Barchowsky A et al (2012) The toxicology education summit: building the future of toxicology through education. Toxicol Sci 127(2):331-8

4. Goitein L et al (2005) The effects of work-hour limitations on resident well-being, patient care, and education in an internal medicine residency program. Arch Intern Med 165:2601-6

5. Maddry JK et al (2014) A comparison of simulation-based education versus lecture-based instruction for toxicology training in emergency medicine residents. J Med Toxicol. doi:10.1007/s13181-014-0401-8

6. Skolnik A (2013) Practice or perish: why bedside toxicology is essential to the survival of our specialty. J Med Toxicol 9:6-8 